\title{
Prevalence of depressive symptoms and its associated factors among healthy community-dwelling older adults living in Australia and the United States
}

Mohammadreza Mohebbi ${ }^{\dagger 1,2}$, Bruno Agustini ${ }^{\dagger 2}$, Robyn L Woods ${ }^{3}$, John J McNeil ${ }^{3}$, Mark R Nelson ${ }^{4}$, Raj C Shah ${ }^{5}$, Van Nguyen ${ }^{1,}{ }^{10}$, Elsdon Storey ${ }^{3}$, Anne M Murray ${ }^{6,7}$, Christopher M Reid ${ }^{3,8}$, Brenda Kirpach $^{6}$, Rory S Wolfe ${ }^{3}$, Jessica E Lockery ${ }^{3}$, Michael Berk ${ }^{2,3,9}$, on behalf of the ASPREE Investigator Group*

1. Deakin University, Biostatistics Unit, Geelong, Australia

2. Deakin University, School of Medicine, IMPACT Strategic Research Centre, Geelong, Australia

3. Department of Epidemiology \& Preventive Medicine, Monash University, Melbourne, VIC, Australia

4. Menzies Institute for Medical Research, University of Tasmania, Hobart TAS, Australia

5. Department of Family Medicine and Rush Alzheimer's Disease Center, Rush University Medical Center, Chicago IL, U.S.

6. Berman Center for Outcomes and Clinical Research, Minneapolis Medical Research Foundation, Hennepin County Medical Center, Minneapolis MN, U.S.

7. Division of Geriatrics, Department of Medicine, Hennepin County Medical Center and University of Minnesota, Minneapolis MN, U.S.

8. School of Public Health, Curtin University, Perth WA, Australia

9. Orygen, the National Centre of Excellence in Youth Health, the Department of Psychiatry and the Florey Institute for Neuroscience and Mental Health, University of Melbourne, Australia

10. La Trobe University, Alfred Health Clinical School, The Alfred Centre, Prahran, Australia

*ASPREE Investigator Group listed on www.aspree.org

${ }^{\dagger}$ Joint first authors

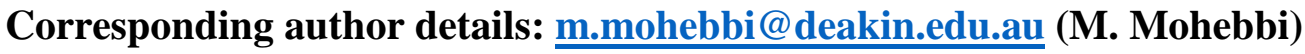

This is the author manuscript accepted for publication and has undergone full peer review but has not been through the copyediting, typesetting, pagination and proofreading process, which may lead to differences between this version and the Version of Record. Please cite this article as doi: 10.1002/gps.5119

This article is protected by copyright. All rights reserved. 


\title{
Word count: 3,417 .
}

\begin{abstract}
Objective: This study was conducted to estimate prevalence rates and factors associated with depressive symptoms indexed by the Centre for Epidemiological Studies - Depression (CESD-10) score in a large sample of community-dwelling healthy older adults from Australia and the United States. Convergent and divergent validity of the CES-D-10 were also examined.

Methods: A total of 19,114 individuals aged $\geq 65$ years were enrolled from a primary prevention clinical trial. Depressive symptoms were classified using the CES-D-10 score $\geq 8$ and $\geq 10$. Gender-specific prevalence for sub-groups according to socio-demographic characteristics were reported and factors associated with depressive symptoms were estimated.
\end{abstract}

Results: The overall prevalence rates of depressive symptoms were 9.8\%, 95\% CI $(8.5,11.2)$ and $5.0 \%, 95 \% \mathrm{CI}(4.0,6.0)$, according to the CES-D-10 score $\geq 8$ and $\geq 10$ respectively. Depressive symptoms were more common in women, individuals with less than 12 years of education, those living alone or in a residential care, ethnic minorities, current smokers and former alcohol users. Convergent and divergent validities of the CES-D-10 were confirmed by observing strong negative association with the SF-12 mental health component and a modest negative association with SF-12 physical component, respectively.

Conclusions: This study reports the prevalence of depressive symptoms in Australian and United States community-dwelling healthy older populations. These findings emphasise the high burden of the condition and factors associated with depressive symptoms, to better inform clinicians and help with early detection and treatment of depression in this age group.

Keywords: mental disorder, depression, prevalence, convergent validity, CES-D-10, late-life depression, older adults. 


\section{Key points:}

1- Depressive symptoms are relatively common in older adults;

2- Several factors associated with depressive symptoms are easily identifiable and should raise suspicion of clinicians regarding the possibility of depression in this population;

3- Women, those less educated, living alone or in a residential care, ethnic minorities, current smokers and former alcohol users represent a vulnerable group for late-life depression. 


\section{Introduction}

The world population is ageing. According to the latest United Nations report, the global population aged 60 years or over numbered 962 million in 2017 and the number of older persons is expected to double again by 2050 , when it is projected to reach nearly 2.1 billion ${ }^{1}$. Depression is ranked by the World Health Organization (WHO) as the single largest contributor to global disability (7.5\% of all years lived with disability in 2015$)^{2}$. In addition, depression is associated with several somatic consequences further increasing its burden of disease ${ }^{3}$. Prevalence rates vary by age but tend to peak in older adulthood (above $7.5 \%$ among females aged 55-74 years, and above 5.5\% among males), according to the latest WHO report ${ }^{2}$. Late-life depression (LLD) is defined as depression that occurs after 65 years of age and significantly impacts and diminishes quality of life in this population ${ }^{4}$.

Previous studies have generated inconsistent findings about the prevalence of mental illness among older adults ${ }^{5}$, although most studies report increasing prevalence rates of depression in old age ${ }^{6}$. The prevalence of major depression in populations aged 75 and older ranges from $4.6 \%$ to $9.3 \%$, and that of depressive disorders from $4.5 \%$ to $37.4 \%^{7}$. Rates of clinically relevant depressive symptoms vary between $7.2 \%$ and $49 \%$ in this population ${ }^{8,9}$. Recent surveys have indicated that around $8 \%$ of community-dwelling Australians aged over 60 years ${ }^{10}$ and $11 \%$ of over 70 years US population experience clinically significant depression 11. A recent review of different depression definitions found a high correlation for depression rating scales and a formal DSM-IV diagnosis, with an estimated prevalence of depressive syndromes in older adults around 9\% ${ }^{12}$. Regardless of cut-off's for diagnosis of major depression, the presence of minor or subthreshold symptoms was shown to severely impact outcomes in older individuals ${ }^{13,14}$.

Depression in later life causes suffering and disability, it is associated and worsens the outcomes of many medical illnesses, increases health costs and increases mortality ${ }^{3,15,16}$. LLD is a major public health issue, yet it tends to be unrecognized by physicians ${ }^{17,18}$. Although rates of depression treatment are increasing ${ }^{19}$, many people still do not have adequate control of depressive symptoms ${ }^{20}$. A recent study of a large national sample found 
that few Americans diagnosed with depression receive guideline-concordant treatment, with racial/ethnic minority populations receiving even less treatment than non-Hispanic whites 21,22

The aim of this study was to determine gender-specific prevalence of depressive symptoms in people aged over 65 years based on the Short form of Centre for Epidemiologic Studies Depression Scale (CES-D-10) ${ }^{23}$ and to provide information across age strata, sex, residential place, language, alcohol consumption and different racial and ethnic groups. As our secondary aim, we examined convergent validity of the CES-D-10 for measuring severity of depressive symptoms in community-dwelling older adults. Based on previous research, we proposed that there would be a similar direction and magnitude of associations between higher CES-D-10 cut-off scores (i.e. cut-off scores 12, 14, and 16) and being female, from racial/ethnic minorities, non-English speaking background, institutional living and/or living alone (versus private household), smoking, lower education and non-occasional and hazardous alcohol consumption ${ }^{7,24-28}$.

\section{Materials and Methods}

In this study, the presence of depressive symptoms among healthy community dwelling older adults was measured using a single validated instrument. This prevalence study is a sub-study of a larger investigation, known as the ASPREE (ASPirin in Reducing Events in the Elderly) study, which is a randomised double-blind placebo-controlled trial examining the efficacy of low-dose aspirin on extending disability-free and dementia-free life in a healthy older population ${ }^{29-31}$. This study is also a component of 'ASPREE-D', which explores the potential of aspirin to prevent the onset of depression in the aged ${ }^{32}$.

\section{Recruitment of sample}

A two-stage recruitment strategy was used in Australia which involved initial recruitment of general practitioners and subsequent recruitment of their patients. In the US, recruitment was 
community-based utilizing a range of methods such as clinic-based, mailing lists, media advertisements, pre-existing registries and electronic medical records. Details of this strategy have been described in detail elsewhere ${ }^{33}$. Selected sites in the US had special focus on recruiting minority groups to enrich the study participants with African American, Hispanic, Native American and other minorities. Minority status was defined by self-report of race/ethnicity in the sociodemographic questionnaire applied by the general practitioner. These groups have a lower age criterion due to a higher burden of disease and a survival disadvantage showed in this population ${ }^{34,35}$.

\section{Inclusion criteria}

Community-dwelling men and women 70 years of age and older (US minority 65 years of age and older) and willing and able to provide informed consent were study inclusion criteria.

\section{Exclusion criteria}

Exclusion criteria included a past history of cardiovascular event or established cardiovascular disease or atrial fibrillation, dementia or a score of $<78$ on Modified MiniMental State examination, disability as defined by severe difficulty or inability to perform any one of the Katz activities of daily living, a condition with a high current or recurrent risk of bleeding, anaemia, a condition likely to cause death within 5 years, current use of other antiplatelet or antithrombotic medication, current use of aspirin for secondary prevention, and uncontrolled hypertension.

\section{Governance}

The ASPREE Steering Committee is responsible for the overall management and conduct of the trial.

\section{Instruments}

CES-D-10

The 10-item version of the Centre for Epidemiologic Studies Depression Scale (CES-D-10) was used ${ }^{36}$. The CES-D-10 is a self-completed questionnaire that scores the severity of 
depressive symptoms in general populations. In brief, participants responded to each item of the scale by rating the frequency of each mood or symptom 'during the past week' on a fourpoint scale. A score is assigned by totalling all items (after reversing the positive mood items), the CES-D-10 scale range from 0 to 30. The CES-D-10 has previously shown comparable accuracy when compared to the full-length 20-item version of the CES-D (kappa $=0.97$ ) in classifying participants with depressive symptoms ${ }^{36}$. Construct validity of the CES-D-10 showed that a single score was reliable and valid measure of depression in an older population ${ }^{37,38}$. For the purposes of the current study, a cut-off of $\geq 8$ was a priori regarded as presence of depressive symptoms. As cut-off scores of $\geq 8$ and $\geq 10$ both showed acceptable validity in measuring depression, these cut-off scores were used to examine factors associated with increased depressive symptoms ${ }^{37}$.

$S F-12$

The 12-item version of the Medical Outcomes Study (SF-12) was used in this study to examine convergent and divergent validity. The SF-12 contains a mental component summary and a physical component summary designed to provide an indication of the mental and physical health of respondents, respectively ${ }^{39}$.

\section{Ethics}

The trial is being conducted according to the Declaration of Helsinki 1964 as revised in 2008, the requirements of the Australian National Statement on Ethical Conduct in Human Research, the federal patient privacy (HIPAA) law and ICH-GCP guidelines and the International Conference of Harmonisation Guidelines for Good Clinical Practice and has been approved by institutional review boards at all sites.

\section{Data analysis}

Descriptive statistics using mean and Standard Deviation ( \pm SD), or number $(\%)$, as appropriate, summarized the participants' characteristics. Prevalence of depressive symptoms was estimated, and $95 \%$ confidence intervals (CIs) were calculated using bootstrap technique. 
The association of socio-demographical factors with depressive symptom was determined using logistic regression models and odds ratios (ORs) and 95\% CIs are reported. All twoway interactions between potential risk factors were assessed in multivariable binary logistic models. However, as there was no important interaction identified (i.e. OR comparisons between subgroups, expressed as a ratio, were all $<10 \%$ different), no interaction term was added to final analysis models. Notably, interactions of country (Australia vs US) with other factors were all non-significant and/ or with negligible effect sizes. This justified the pooling of data across the two countries for further analyses. Convergent validity of the CES-D-10 as a tool for measuring severity of symptoms and prevalence was assessed by examining ORs and $95 \%$ CIs estimated from multivariate binary logistic models.

Convergent and Divergent Validity of CES-D-10 score was validated by examining Pearson correlation coefficients. Convergent validity of the CES-D-10 as a tool for measuring severity of symptoms prevalence by considering CES-D-10 $\geq 12$ and $\geq 14$ and $\geq 16$ cut-offs was assessed by examining ORs and 95\% CIs estimated from multivariate binary logistic models.

\section{Results}

\section{Participants' profile}

Table 1 shows sample characteristics for men and women. Of the 19,114 participants, 16,703 (87.4\%) were from Australia and 2,411 (12.6\%) from the US. Mean age was 75 years and 10,782 (56.4\%) were female. 12,779 (66.9\%) participants lived in a private home with family, friends or spouse, 18,263 (95.6\%) were of English-speaking background, 4,276 $(22.4 \%)$ were born overseas, and 10,955 (57.3\%) had 12 years or more formal education. Of 1,664 minority participants, 1,323 (80\%) were from the United States. Current smoking was reported by $735(3.9 \%)$ and 14,642 (76.6\%) were current alcohol consumers.

\section{Prevalence of depressive symptoms}

This article is protected by copyright. All rights reserved. 
There were 4,236 (22.16\%) participants with no depressive symptoms (i.e. CES-D-10 score = $0)$; $19.04 \%(2,052)$ in females, and $26.21 \%(2,184)$ in males and less than $1 \%$ of the total population had a CES-D-10 score of $\geq 15$.

Overall 1,879 (9.8\%), 95\% CI $(8.5,11.2)$ had a CES-D-10 score $\geq 8,1,248(11.6 \%), 95 \%$ CI $(9.6,13.5)$ in females, and $631(7.6 \%), 95 \%$ CI $(5.8,9.3)$ in males. Considering a CES-D-10 score $\geq 10$ as cut-off for depressive symptoms, there was a total of 953 (5.0\%), 95\% CI (4.0, 6.0) participants, 642 (6\%), 95\% CI $(4.5,7.4)$ females, and 311 (3.7), 95\% CI (2.4, 5.0) males. Table 2 summarises prevalence of depressive symptoms according to demographics and associated factors by gender breakdown. In general, depressive symptoms were more prevalent in women, individuals educated for 12 years or less, living alone or in residential care, ethnic minorities, current smokers and those reporting poor mental and physical health. Former alcohol users had a higher prevalence of depressive symptoms and current alcohol consumers and the no-alcohol group had a similar prevalence of depressive symptomatology.

\section{Exploring model-adjusted associations}

Depressive symptoms were more likely in females $\left[\mathrm{OR}_{(\mathrm{CES}-\mathrm{D}-10 \geq 8)}=1.5 ; 95 \% \mathrm{CI}(1.3,1.6)\right.$, and $\left.\mathrm{OR}_{(\mathrm{CES}-\mathrm{D}-10 \geq 10)}=1.5 ; 95 \% \mathrm{CI}(1.3,1.7)\right]$, but there was no age by gender interaction. Presence of depressive symptoms was not associated with age groups $(\leq 74,75-84$, and $\geq$ 85). Table 3 shows factors potentially associated with depressive symptoms. In general, those who lived in a residential home (supervised care or assisted living) or at home alone were more likely to have depressive symptoms compared with those living at home with family, friends or a spouse. Living in a residential home was strongly associated with depressive symptoms. In such circumstances, females had at least double the odds and males had more than two and half times higher odds of presenting with increased depressive symptoms. The low number of participants residing in residential homes in our study may impact the generalisability of this finding. Less than 12 years of education, current smoking and being a racial minority (non-white) were all moderately associated (i.e. OR<2) with depressive symptoms. Language (English vs. non-English) and being from Latino ethnicity were not significantly associated with symptomatology. Compared with respondents who were current 
alcohol users, those who were previous alcohol users were almost one and half times more likely to have depressive symptoms. Among those who reported being current alcohol users, drinking more than five standard drinks per day was a significant factor although no dose response association was evident. Respondents who reported more drinking on the weekend did not have significantly higher odds of depressive symptoms.

\section{Convergent and Divergent Validity}

There was an inverse association between the SF-12 mental component score and the overall CES-D-10 score [r= $-0.45 ; 95 \%$ CI $(-0.47,-0.44)]$, illustrating convergent validity. Divergent validity of the CES-D-10 was assessed by examining correlation with the SF-12 physical component score. As expected, the CES-D-10 had low correlation with this scale $[\mathrm{r}=-0.18$, $95 \%$ CI $(-0.20,-0.17)]$.

Convergent validity of the CES-D-10 was explored by comparing the associations (model adjusted ORs) at cut-off scores of 12, 14 or 16 with age, gender, race, language, living status, smoking, education and alcohol consumption with the corresponding associations at cut-off scores of 8 and 10 (i.e. adjusted ORs from Table S1). As Table S1 illustrated, being female, from racial ethnic minorities, non-English speaking background, institutional living, living alone, smoking, lower education (i.e. less than 12 years formal education) and hazardous alcohol consumption (i.e. more than 5 drinks per day) were positively associated with higher depressive scores. Generally, association patterns were similar for cut-off scores of 12, 14 or 16 compared with proposed cut-off scores (i.e. 8 and 10).

\section{Discussion}

These findings are consistent with those of other epidemiological studies conducted in the United States, Australia and worldwide in demonstrating that the presence of depressive symptoms is common in older populations ${ }^{5,11,40-42}$. The CES-D-10 cut-off of $\geq 8$ showed closest similarity to other depression definitions in population-based studies of older adults and had the higher validity for screening purposes ${ }^{12}$. These data are also consistent in 
highlighting the increased prevalence of depression among females ${ }^{8}$. In previous studies in Australian community-dwelling older women and men, enrolled in the Geelong Osteoporosis Study, the prevalence of any mood disorder, including major depressive disorder, minor depression and bipolar disorder was two times greater in women (8.9\%) compared with men $(3.8 \%)^{43,44}$.

Previous studies using different study designs have found prevalence rates of depressive symptoms in older people ranging from $4.5 \%$ to $49 \%^{7-9,41}$. There is a debate over the source and the causes of the heterogeneity in prevalence of depressive symptoms in this population. Person-related factors including sample setting (e.g. community, outpatient clinic, and nursing home), inclusion/exclusion for cognitive impairment, and the racial/ethnic composition of the sample could each be a source of variation. The definition of depression used in these studies was also highly variable, and this is likely to have had a major impact on estimates. Type of instrument used is also a source of variation. Surveys that use formal diagnostic criteria (i.e. ICD-10 or DSM-IV) tend to yield lower prevalence estimates than those that assessed depression using scales. However, a recent large study show high correlations between DSM-IV criteria and scale-based definitions of depressive symptoms ${ }^{12}$. Varying sample sizes may also influence the robustness of given prevalence estimates.

The CES-D-10 convergent and divergent validity was examined in this sample. Significant negative associations between the CES-D-10 score and SF-12 mental component score and lack of association between the CES-D-10 score and SF-12 physical component score support our proposed relationships. In addition, there were significant associations between the CESD-10 higher cut-offs (i.e. $\geq 12,14$, and 16) and gender, race, language, living status, smoking, education and alcohol consumption. In addition, convergent and divergent validity of the CES-D-10 score were assessed by examining the CES-D-10 pairwise correlations with the mental and physical components of SF-12 quality of life survey respectively ${ }^{45,46}$. The strength of these associations were also similar to the CES-D-10 proposed cut-offs (i.e. $\geq 8$, and 10) for presence of depressive symptoms. Overall, this suggests that the CES-D-10 appears to be an effective instrument for screening and following symptom severity in older people. 
There are some limitations of this validation study. Because ASPREE participants were a volunteer sample selected as a healthy population across Australia and the US, the study population might not be representative of the broader population. In particular, exclusion of unwell individuals may have resulted in lower prevalence rates of depression. As such we considered the existing sample as a single sample of healthy older participants and did not report country-specific rates. The results of this study are based on participants' scores on the CES-D-10, a validated screening tool used to identify persons who have experienced symptoms of depression during the previous week and who thus may be at risk for depression; it is not a formal diagnostic test for clinical depression, notwithstanding reasonable correlations between these two domains in the literature ${ }^{38,47}$. Furthermore, data were collected from just one point in time, and thus only association, not causality, can be inferred from the results. An alternative study design, such as a cohort study with multiple CES-D-10 measurements and alternative evaluation of depression, such as clinical diagnosis, could provide an opportunity to examine causal pathways. Our study did not compare the CES-D-10 with clinical diagnoses of depression to examine predictive validity. Criterion related validity was not assessed in this study. Further studies of the psychometric properties of the CES-D-10 could include the assessment of the scale compared with a formal psychiatric diagnosis to estimate the better cut-offs. Also, a self-reported question about past depression history was only asked from a small fraction of participants, so reporting relapse/recurrence rates or undiagnosed depression rates was not possible.

Major strengths of this study include the use of a reliable, standardised instrument that was validated for older people and that has a high correlation with a formal psychiatric diagnosis in this population ${ }^{38,48,49}$. Regardless of actual diagnosis, the presence of depressive symptoms significantly impact this population ${ }^{4,13}$ and this tool has proven its use for screening in this circumstances ${ }^{50}$. Other important features were (a) the large sample size, when compared with other similar studies, (b) accurate results as reflected in the small confidence intervals for regression models estimates, and (c) the fact that the sample was community-based healthy older participants in a randomised trial that benefited from high quality methodology in questionnaire administration and data collection. Moreover, the current study identified a 
broad range of associations that varied according to gender, living status, smoking status, race, cultural and linguistic diversity, and alcohol consumption.

In conclusion, this very large study confirms and provides up-to-date reference for the high prevalence of depressive symptomatology in a generally healthy older population from highincome countries, as well as its associated factors including gender, living status, smoking, race, cultural and linguistic diversity, background level of education and alcohol consumption. Awareness of these factors by clinicians might improve early detection and treatment of high-risk individuals, as well as inform policy makers regarding the rising public health issue of depression in later life.

\section{Data Available on Request}

Data is available on request through ASPREE (ASPirin in Reducing Events in the Elderly) data access committee (contact email: aspree@monash.edu).

\section{Acknowledgements}

The authors acknowledge the efforts of research personnel and long-term involvement of participants of the ASPREE Study. The study is supported by the National Institute on Aging and the National Cancer Institute at the National Institutes of Health (grant number U01AG029824); the National Health and Medical Research Council of Australia (grant numbers 334047, 1127060); Monash University (Australia); the Victorian Cancer Agency (Australia). MB is supported by a NHMRC Senior Principal Research Fellowship (1059660) and CMR is supported by a NHMRC Senior Research Fellowship (1045862). 


\section{References}

1. United Nations, Department of Economic and Social Affiars Population Division. World Population Ageing 2017 - Highlights.; 2017. doi:ST/ESA/SER.A/348

2. World Health Organization. Depression and other common mental disorders: global health estimates. Geneva World Heal Organ. 2017:1-24. doi:CC BY-NC-SA 3.0 IGO

3. Penninx BWJH, Milaneschi Y, Lamers F, Vogelzangs N. Understanding the somatic consequences of depression: biological mechanisms and the role of depression symptom profile. BMC Med. 2013;11:129. doi:10.1186/1741-7015-11-129

4. Alexopoulos GS. Depression in the elderly. Lancet. 2005;365(9475):1961-1970. doi:10.1016/S0140-6736(05)66665-2

5. Weber K, Da Ronch C, Canuto A, et al. Prevalence of mental disorders in elderly people: The European MentDis_ICF65+ study. Br J Psychiatry. 2016;210(02):125131. doi:10.1192/bjp.bp.115.180463

6. Schulz H, Härter M, Andreas S, Volkert J, Wlodarczyk O. The prevalence of mental disorders in older people in Western countries - a meta-analysis. Ageing Res Rev. 2012;12(1):339-353. doi:10.1016/j.arr.2012.09.004

7. Luppa M, Sikorski C, Luck T, et al. Age- and gender-specific prevalence of depression in latest-life - Systematic review and meta-analysis. J Affect Disord. 2012;136(3):212221. doi:10.1016/j.jad.2010.11.033

8. Djernes JK. Prevalence and predictors of depression in populations of elderly: A review. Acta Psychiatr Scand. 2006;113(5):372-387. doi:10.1111/j.16000447.2006.00770.x 
9. Miszkurka M, Zunzunegui MV, Ylli A, Deshpande N, Guralnik J, Phillips SP. Clinically relevant depression in old age: An international study with populations from Canada, Latin America and Eastern Europe. Psychiatry Res. 2016;241:236-241. doi:10.1016/j.psychres.2016.04.096

10. Pirkis J, Pfaff J, Williamson M, et al. The community prevalence of depression in older Australians. J Affect Disord. 2009;115(1-2):54-61. doi:10.1016/j.jad.2008.08.014

11. Steffens DC, Fisher GG, Langa KM, Potter GG, Plassman BL. Prevalence of depression among older Americans: The aging, demographics and memory study. Int Psychogeriatrics. 2009;21(5):879-888. doi:10.1017/S1041610209990044

12. Sjöberg L, Karlsson B, Atti AR, Skoog I, Fratiglioni L, Wang HX. Prevalence of depression: Comparisons of different depression definitions in population-based samples of older adults. J Affect Disord. 2017;221(April):123-131. doi:10.1016/j.jad.2017.06.011

13. Cuijpers P, Vogelzangs N, Twisk J, Kleiboer A, Li J, Penninx BW. Differential mortality rates in major and subthreshold depression: Meta-analysis of studies that measured both. Br J Psychiatry. 2013;202(1):22-27. doi:10.1192/bjp.bp.112.112169

14. Da Silva SA, Scazufca M, Menezes PR. Population impact of depression on functional disability in elderly: Results from "são Paulo Ageing \& Health Study" (SPAH). Eur Arch Psychiatry Clin Neurosci. 2013;263(2):153-158. doi:10.1007/s00406-012-0345-4

15. Katon WJ, Lin E, Russo J, Unützer J. Increased medical costs of a population-based sample of depressed elderly patients. Arch Gen Psychiatry. 2003;60(9). doi:10.1001/archpsyc.60.9.897

16. Grigoletti L, Perini G, Rossi A, et al. Mortality and cause of death among psychiatric patients: A 20-year case-register study in an area with a community-based system of care. Psychol Med. 2009;39(11):1875-1884. doi:10.1017/S0033291709005790

17. Mitchell AJ, Rao S, Vaze A. Do primary care physicians have particular difficulty identifying late-life depression? A meta-analysis stratified by age. Psychother Psychosom. 2010;79(5):285-294. doi:10.1159/000318295

18. Almeida OP, Alfonso H, Pirkis J, et al. A practical approach to assess depression risk and to guide risk reduction strategies in later life. Int Psychogeriatrics. 2011;23(2):280-291. doi:10.1017/S1041610210001870

19. Kok RM, Reynolds CF. Management of depression in older adults: A review. JAMA J Am Med Assoc. 2017;317(20):2114-2122. doi:10.1001/jama.2017.5706

20. Kessler RC, Ph D, Birnbaum H, et al. Age differences in the prevelance and comorbidity of DSM-IV major depressive epoisodes: Results from the WHO World Mental Health Survey Initiative. Depress Anxiety. 2010;27(4):351-364. doi:10.1002/da.20634.Age 
21. González HM, Tarraf W, Whitfield KE, Vega WA. The epidemiology of major depression and ethnicity in the United States. J Psychiatr Res. 2010;44(15):1043-1051. doi:10.1016/j.jpsychires.2010.03.017

22. González HM, Vega WA, Williams DR, Tarraf W, West BT, Neighbors HW. Depression care in the United States: too little for too few. 2011;67(1):37-46. doi:10.1001/archgenpsychiatry.2009.168.Depression

23. Events L. The CES-D Scale -ReAoselfepression Scale for Research in the General Population. Appl Psychol Meas. 1977;1(3):385-401. doi:10.1177/014662167700100306

24. Aziz R, Steffens DC. What Are the Causes of Late-Life Depression? Psychiatr Clin North Am. 2013;36(4):497-516. doi:10.1016/j.psc.2013.08.001

25. Almeida OP, Alfonso H, Pirkis J, et al. A practical approach to assess depression risk and to guide risk reduction strategies in later life. Int Psychogeriatrics. 2011;23(2):280-291. doi:10.1017/S1041610210001870

26. Almeida OP. Prevention of depression in older age. Maturitas. 2014;79(2):136-141. doi:10.1016/j.maturitas.2014.03.005

27. Riolo SA, Nguyen TA, Greden JF, King CA. Prevalence of depression by race/ethnicity: Findings from the national health and nutrition examination survey III. Am J Public Health. 2005;95(6):998-1000. doi:10.2105/AJPH.2004.047225

28. A. H, K. G. Access to a community aged psychiatry service by elderly from nonEnglish-speaking backgrounds. Int J Geriatr Psychiatry. 2002;17(7):623-628. http://ovidsp.ovid.com/ovidweb.cgi?T=JS\&PAGE=reference $\& D=$ emed5\&NEWS=N\& $\mathrm{AN}=2002260219$.

29. McNeil JJ, Nelson MR, Woods RL, et al. Effect of Aspirin on All-Cause Mortality in the Healthy Elderly. N Engl J Med. 2018:NEJMoa1803955. doi:10.1056/NEJMoa1803955

30. McNeil JJ, Woods RL, Nelson MR, et al. Effect of Aspirin on Disability-free Survival in the Healthy Elderly. N Engl J Med. 2018:NEJMoa1800722. doi:10.1056/NEJMoa1800722

31. McNeil JJ, Wolfe R, Woods RL, et al. Effect of Aspirin on Cardiovascular Events and Bleeding in the Healthy Elderly. N Engl J Med. 2018:NEJMoa1805819. doi:10.1056/NEJMoa1805819

32. Berk M, Woods RL, Nelson MR, et al. ASPREE-D: Aspirin for the prevention of depression in the elderly. Int Psychogeriatrics. 2016;28(10):1741-1748. doi:10.1017/S104161021600079X

33. Grimm R, McNeil JJ, Applegate W, et al. Study design of ASPirin in Reducing Events in the Elderly (ASPREE): A randomized, controlled trial. Contemp Clin Trials. 
2013;36(2):555-564. doi:10.1016/j.cct.2013.09.014

34. McNeil JJ, Woods RL, Nelson MR, et al. Baseline Characteristics of Participants in the ASPREE (ASPirin in Reducing Events in the Elderly) Study. Journals Gerontol Ser A. 2017;00(00):1-8. doi:10.1093/gerona/glw342

35. González HM, Tarraf W. Comorbid cardiovascular disease and major depression among ethnic and racial groups in the United States. Int Psychogeriatrics.

2013;25(5):833-841. doi:10.1017/S1041610212002062

36. Andresen EM, Malmgren JA, Carter WB, Patrick DL. Screening for depression in well older adults: evaluation of a short form of the CES-D (Center for Epidemiologic Studies Depression Scale). Am J Prev Med. 1993;10(2):77-84. doi:10.4236/health.2013.53A078

37. Mohebbi M, Nguyen V, McNeil JJ, et al. Psychometric properties of a short form of the Center for Epidemiologic Studies Depression (CES-D-10) scale for screening depressive symptoms in healthy community dwelling older adults. Gen Hosp Psychiatry. 2017;(May):1-9. doi:10.1016/j.genhosppsych.2017.08.002

38. Irwin, M; Artin, KH; Oxman M. Screening for Depression in the Older Adult. Arch Intern Med. 1999;159:1701-1704.

39. Gandek B, Ware JE, Aaronson NK, et al. Cross-validation of item selection and scoring for the SF-12 Health Survey in nine countries: Results from the IQOLA Project. J Clin Epidemiol. 1998;51(11):1171-1178. doi:10.1016/S08954356(98)00109-7

40. Loxton D, Byrne JM, Rich JL, Byles JE. Prevalence and Correlates of Depression among Australian Women: A Systematic Literature Review The Priority Research Centre for Gender, Health and Ageing. 2010:98.

https://www.newcastle.edu.au/_data/assets/pdf_file/0006/137526/Beyondblue-report160610.pdf.

41. Volkert J, Schulz H, Härter M, Wlodarczyk O, Andreas S. The prevalence of mental disorders in older people in Western countries - a meta-analysis. Ageing Res Rev. 2013;12:339-353. doi:10.1016/j.arr.2012.09.004

42. Ausín B, Muñoz M, Santos-Olmo AB, Pérez-Santos E, Castellanos MA. Prevalence of Mental Disorders in the Elderly in the Community of Madrid: Results of the MentdisICF65+ Study. Span J Psychol. 2017;20(2017):1-11. doi:10.1017/sjp.2017.3

43. Williams L, Jacka F, Pasco J, et al. The prevalence of mood and anxiety disorders in Australian women. Australas Psychiatry. 2010:250-255. doi:10.3109/10398561003731155

44. Williams LJ, Jacka FN, Pasco JA, et al. The prevalence and age of onset of psychiatric disorders in Australian men. 2016. doi:10.1177/0004867415614105 
45. Walsh TL, Mdt D, Homa K, et al. Screening for depressive symptoms in patients with chronic spinal pain using the SF-36 Health Survey. 2006;6:316-320.

doi:10.1016/j.spinee.2005.11.004

46. Yu DSF, Yan ECW, Kai C. Interpreting SF-12 mental component score $\quad \square$ : an investigation of its convergent validity with CESD-10. Qual Life Res. 2015:22092217. doi:10.1007/s11136-015-0959-X

47. Haringsma R, Engels GI, Beekman ATF, Spinhoven P. The criterion validity of the Center for Epidemiological Studies Depression Scale (CES-D) in a sample of selfreferred elders with depressive symptomatology. Int J Geriatr Psychiatry. 2004;19(6):558-563. doi:10.1002/gps.1130

48. Vilagut G, Forero CG, Barbaglia G, Alonso J. Screening for depression in the general population with the center for epidemiologic studies depression (ces-d): A systematic review with meta-analysis. PLoS One. 2016;11(5):1-17. doi:10.1371/journal.pone.0155431

49. Gallo LC, Perreira K, Camacho A, et al. Measurement properties of the Center for Epidemiologic Studies Depression Scale (CES-D 10): Findings from HCHS/SOL. Psychol Assess. 2016;29(4):372-381. doi:10.1037/pas0000330

50. Cheng ST, Chan ACM. The Center for Epidemiologic Studies Depression Scale in older Chinese: Thresholds for long and short forms. Int J Geriatr Psychiatry. 2005;20(5):465-470. doi:10.1002/gps.1314 
Table 1 - Demographic characteristics of male and female participants.

\begin{tabular}{|c|c|c|}
\hline Demographic categories & $\begin{array}{c}\text { Male } \\
(n=8,332) \\
n(\%)^{*}\end{array}$ & $\begin{array}{c}\text { Female } \\
(\boldsymbol{n}=\mathbf{1 0 , 7 8 2}) \\
n(\%)^{*}\end{array}$ \\
\hline Age group, M (SD) & $75.0(4.5)$ & $75.2(4.6)$ \\
\hline \multicolumn{3}{|l|}{ Country } \\
\hline Australia & $7,523(90.3)$ & $9,180(85.1)$ \\
\hline The United States & $809(9.7)$ & $1,602(14.9)$ \\
\hline \multicolumn{3}{|l|}{ Living status } \\
\hline At home alone & $1,731(20.8)$ & $4,521(41.9)$ \\
\hline $\begin{array}{l}\text { At home with family, friends or a } \\
\text { spouse }\end{array}$ & $6,570(78.9)$ & $6,209(57.6)$ \\
\hline In a residential home ${ }^{1}$ & $31(0.4)$ & $52(0.5)$ \\
\hline \multicolumn{3}{|l|}{ Ethnicity } \\
\hline Hispanic or Latino & $202(2.4)$ & $286(2.7)$ \\
\hline Not Hispanic or Latino & $8,129(97.6)$ & $10,496(97.4)$ \\
\hline \multicolumn{3}{|l|}{ Race } \\
\hline White/ Caucasian & $7,793(93.5)$ & $9,905(91.9)$ \\
\hline Black/ African American & $310(3.7)$ & $599(5.6)$ \\
\hline Other & $148(2.8)$ & $162(2.2)$ \\
\hline \multicolumn{3}{|l|}{ Language } \\
\hline English & $7,919(95.0)$ & $10,344(95.9)$ \\
\hline Not English & $413(5.0)$ & $438(4.1)$ \\
\hline \multicolumn{3}{|l|}{ Born overseas } \\
\hline No & $6,231(74.8)$ & $8,607(79.8)$ \\
\hline Yes & $2,101(25.2)$ & $2,175(20.2)$ \\
\hline \multicolumn{3}{|l|}{ Education } \\
\hline$\leq 12$ years & $4,600(55.2)$ & $6,355(58.9)$ \\
\hline$>12$ years & $3,732(44.8)$ & $4,426(41.1)$ \\
\hline \multicolumn{3}{|l|}{ Smoking status } \\
\hline Current & $383(4.6)$ & $352(3.3)$ \\
\hline Former & $4,362(52.4)$ & $3,437(31.9)$ \\
\hline Never & $3,587(43.0)$ & $6,993(64.9)$ \\
\hline \multicolumn{3}{|l|}{ Alcohol drinking $^{\#}$} \\
\hline Current & $6,932(83.2)$ & $7,710(71.5)$ \\
\hline Former & $607(7.3)$ & $529(4.9)$ \\
\hline Never & $793(9.5)$ & $2,543(23.6)$ \\
\hline
\end{tabular}

This article is protected by copyright. All rights reserved. 


\begin{tabular}{lcc}
\hline $\begin{array}{l}\text { Alcohol use (days/week) } \\
\quad \text { < once per week }\end{array}$ & $1,972(26.2)$ & $3,448(41.9)$ \\
1-6 days per week & $3,595(47.6)$ & $3,277(39.7)$ \\
everyday & $1,971(26.2)$ & $1,514(18.4)$ \\
\hline Number of alcohol drinks & & \\
$\quad$ 1-4 drinks & $6,890(91.4)$ & $8,165(99.1)$ \\
5-8 drinks & $519(6.9)$ & $55(0.7)$ \\
$\geq 9$ drinks & $129(1.7)$ & $19(0.2)$ \\
\hline Drink more alcohol on weekend $^{\#}$ & & \\
$\quad$ No & $6,393(84.8)$ & $7,491(90.9)$ \\
$\quad$ Yes & $1,146(15.2)$ & $748(9.1)$ \\
\hline Past depression history & & \\
Unsure & $37(0.4)$ & $70(0.7)$ \\
No & $2,454(29.5)$ & $2,739(25.4)$ \\
Yes & $501(6.0)$ & $1,166(10.8)$ \\
\hline
\end{tabular}

Note: ${ }^{1}$ supervised care or assisted living; * except for age - continuous variable. M: Mean, SD: Standard deviation; \# nondrinkers have been excluded; ${ }^{\S}$ the question of a history of depression were only asked after June 2013.

This article is protected by copyright. All rights reserved. 
Table 2 - The prevalence of depression symptoms in males and females determined by the CES-D-10 cut-off $\geq 8$

\begin{tabular}{|c|c|c|c|c|}
\hline \multirow{3}{*}{ Demographic categories } & \multicolumn{4}{|c|}{ CES-D-10 $\geq 8$} \\
\hline & \multicolumn{2}{|r|}{ Male } & \multicolumn{2}{|c|}{ Female } \\
\hline & $\%$ & $95 \% \mathrm{CI}$ & $\%$ & $95 \% \mathrm{CI}$ \\
\hline Total prevalence & 7.6 & $6.4,8.8$ & 11.6 & $10.1,13.0$ \\
\hline $\begin{array}{l}\text { Age group (years) } \\
\leq 74 \\
75-84 \\
\geq 85\end{array}$ & $\begin{array}{l}7.4 \\
7.5 \\
10.4 \\
\end{array}$ & $\begin{array}{l}6.7,8.2 \\
6.6,8.5 \\
7.4,14.5\end{array}$ & $\begin{array}{l}11.5 \\
11.8 \\
10.8\end{array}$ & $\begin{array}{l}10.7,12.3 \\
10.9,12.8 \\
8.2,14.1 \\
\end{array}$ \\
\hline $\begin{array}{l}\text { Country } \\
\text { Australia } \\
\text { The United States }\end{array}$ & $\begin{array}{l}7.4 \\
8.9 \\
\end{array}$ & $\begin{array}{l}4.6,13.2 \\
6.2,8.7\end{array}$ & $\begin{array}{l}13.2 \\
11.3 \\
\end{array}$ & $\begin{array}{l}9.1,17.4 \\
9.8,12.8\end{array}$ \\
\hline $\begin{array}{l}\text { Living status } \\
\text { At home alone } \\
\text { At home with family, } \\
\text { friends or a spouse } \\
\text { In a residential home }\end{array}$ & $\begin{array}{l}12.0 \\
6.4 \\
16.1\end{array}$ & $\begin{array}{l}8.9,15.1 \\
5.1,7.6 \\
(5 / 31)^{*}\end{array}$ & $\begin{array}{l}13.1 \\
10.4 \\
19.2\end{array}$ & $\begin{array}{l}10.7,15.5 \\
8.6,12.2 \\
(10 / 52)^{*}\end{array}$ \\
\hline $\begin{array}{l}\text { Ethnicity } \\
\text { Hispanic or Latino } \\
\text { Not Hispanic or Latino }\end{array}$ & $\begin{array}{l}10.4 \\
7.5 \\
\end{array}$ & $\begin{array}{l}1.8,19.0 \\
6.3,8.7\end{array}$ & $\begin{array}{l}15.0 \\
11.5\end{array}$ & $\begin{array}{l}5.0,25.0 \\
10.1,12.9\end{array}$ \\
\hline $\begin{array}{l}\text { Race } \\
\text { White } \\
\text { African American } \\
\text { Other }\end{array}$ & $\begin{array}{l}7.3 \\
12.6 \\
8.8 \\
\end{array}$ & $\begin{array}{l}2.7,18.3 \\
7.4,20.5 \\
4.5,16.4 \\
\end{array}$ & $\begin{array}{l}11.3 \\
15.4 \\
18.5 \\
\end{array}$ & $\begin{array}{l}6.1,19.8 \\
9.5,23.9 \\
12.2,27.1 \\
\end{array}$ \\
\hline $\begin{array}{l}\text { Language } \\
\text { English } \\
\text { Not English } \\
\end{array}$ & $\begin{array}{l}7.6 \\
6.5 \\
\end{array}$ & $\begin{array}{l}6.4,8.9 \\
1.4,11.7 \\
\end{array}$ & $\begin{array}{l}11.5 \\
12.6\end{array}$ & $\begin{array}{l}10.1,13.0 \\
5.1,20.1 \\
\end{array}$ \\
\hline $\begin{array}{l}\text { Education (years) } \\
\text { Less than } 12 \\
\text { More than } 12 \\
\end{array}$ & $\begin{array}{l}8.1 \\
6.9 \\
\end{array}$ & $\begin{array}{l}6.4,9.8 \\
5.2,8.6\end{array}$ & $\begin{array}{l}12.3 \\
10.6\end{array}$ & $\begin{array}{l}10.4,14.1 \\
8.4,12.7\end{array}$ \\
\hline $\begin{array}{l}\text { Smoking status } \\
\text { Current } \\
\text { Former or never } \\
\end{array}$ & $\begin{array}{l}13.6 \\
7.3 \\
\end{array}$ & $\begin{array}{l}6.3,20.9 \\
6.1,8.5 \\
\end{array}$ & $\begin{array}{l}16.5 \\
11.4\end{array}$ & $\begin{array}{l}7.0,26.1 \\
10.0,12.9\end{array}$ \\
\hline $\begin{array}{l}\text { Alcohol use } \\
\text { Current } \\
\text { Former } \\
\text { Never }\end{array}$ & $\begin{array}{l}7.2 \\
12.2 \\
7.1 \\
\end{array}$ & $\begin{array}{l}6.1,8.6 \\
7.7,18.7 \\
4.2,11.7 \\
\end{array}$ & $\begin{array}{l}11.2 \\
15.3 \\
11.9 \\
\end{array}$ & $\begin{array}{l}7.6,16.2 \\
11.7,19.8 \\
6.2,21.8 \\
\end{array}$ \\
\hline $\begin{array}{l}\text { Physical health } \\
\leq 50 \text { score }\end{array}$ & 10.6 & $8.5,12.7$ & 14.2 & $12.0,16.3$ \\
\hline
\end{tabular}




\begin{tabular}{|l|ll|ll|}
$>50$ score & 5.3 & $3.9,6.6$ & 8.7 & $6.8,10.5$ \\
\hline $\begin{array}{l}\text { Mental health } \\
\leq 50 \text { score }\end{array}$ & 26.7 & $21.7,31.6$ & 31.3 & $26.4,35.8$ \\
$>50$ score & 4.0 & $3.0,4.9$ & 6.6 & $5.3,7.8$ \\
\hline
\end{tabular}

Note: CESD-10: Center for epidemiologic Studies Depression Scale (1o items), CI: Confidence Interval. ${ }^{1}$ supervised care or assisted living. * not enough data to calculate confidence interval. 


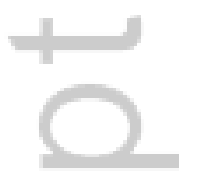

This article is protected by copyright. All rights reserved. 
Table 3 - Factors associated with depressive symptoms as measured by the CES-D-10 cut-offs $\geq 8$ and $\geq 10$

\begin{tabular}{|c|c|c|c|c|c|}
\hline \multicolumn{2}{|l|}{ CES-D-10 cut-off } & \multicolumn{2}{|c|}{ CES-D-10 $\geq 8$} & \multicolumn{2}{|c|}{ CES-D-10 $\geq 10$} \\
\hline \multicolumn{2}{|l|}{ Factors } & $\begin{array}{l}\text { Female } \\
\text { OR }(95 \% \text { CI })\end{array}$ & $\begin{array}{l}\text { Male } \\
\text { OR }(95 \% \text { CI })\end{array}$ & $\begin{array}{l}\text { Female } \\
\text { OR }(95 \% \text { CI })\end{array}$ & \begin{tabular}{|l} 
Male \\
OR $(95 \%$ CI $)$
\end{tabular} \\
\hline \multirow[t]{2}{*}{ 1. Age $^{1}$} & $75-84$ years & $0.9(0.9-1.12)$ & $0.9(0.8-1.2)$ & $0.9(0.8-1.2)$ & $0.9(0.8-1.2)$ \\
\hline & $85+$ years & $\begin{array}{l}0.8(0.6-1.15) \\
*\end{array}$ & $\begin{array}{l}1.2(0.8-1.8) \\
*\end{array}$ & $\begin{array}{l}0.8(0.5-1.2) \\
*\end{array}$ & $\begin{array}{l}0.8(0.5-1.6) \\
*\end{array}$ \\
\hline \multirow[t]{2}{*}{ 2. Living status } & At home alone & $1.3(1.1,1.4)$ & $1.9(1.6,2.3)$ & $1.4(1.2,1.6)$ & $2.1(1.6,2.7)$ \\
\hline & In a residential home & $2.2(1.1,4.4)$ & $2.7(1.0,7.0)$ & $2.1(0.8,5.2)$ & $4.6(1.6,13.5)$ \\
\hline 3. Education & $\leq 12 \mathrm{yrs}$ education & $1.2(1.1,1.4)^{* *}$ & $1.1(1.0,1.4)$ & $1.1(1.0,1.3)$ & $1.3(1.0,1.6)$ \\
\hline 4. Smoking history & Current smoker & $1.4(1.1,1.9)^{* *}$ & $1.8(1.3,2.4)^{* *}$ & $1.6(1.1,2.3)^{*}$ & $2.4(1.6,3.4)^{* *}$ \\
\hline 5. Race & Non-White & $1.6(1.3,1.9)^{* *}$ & $1.4(1.0,1.9)^{*}$ & $1.7(1.3,2.3)^{* *}$ & $1.2(0.8,1.8)$ \\
\hline 6. Race & African American & $1.4(1.1,1.08)^{*}$ & $1.4(1.0,2.0)$ & $1.6(1.2,2.1) *$ & $1.3(0.8,2.2)$ \\
\hline 7. Ethnicity & Latino & $1.4(1.0,1.9)$ & $1.4(0.9,2.2)$ & $1.5(1.0,2.3)$ & $1.5(0.8,2.80)$ \\
\hline 8. Language & Non-English & $1.1(0.8,1.5)$ & $0.8(0.6,1.2)$ & $1.1(0.7,1.6)$ & $0.8(0.5,1.4)$ \\
\hline \multirow[t]{2}{*}{ 9. Alcohol used } & & & $* *$ & & $*$ \\
\hline & Former & $1.3(1.0,1.7)$ & $1.6(1.2,2.1)$ & $1.3(0.9,1.8)$ & $1.6(1.1,2.3)$ \\
\hline \multirow{3}{*}{$\begin{array}{l}\text { 10. Number of alcohol } \\
\text { (drinks per day) }\end{array}$} & Never & $1_{* *}^{1.0}(0.9,1.2)$ & $\begin{array}{l}0.9(0.7,1.2) \\
* *\end{array}$ & $1.0(0.9,1.3)$ & $0.9(0.6,1.3)$ \\
\hline & 5-8 Drinks & $2.2(1.2,4.2)$ & $1.2(0.9,1.7)$ & $1.8(0.8,4.3)$ & $1.4(0.9,2.1)$ \\
\hline & $\geq 9$ Drinks & $1.8(0.6,5.5)$ & $2.0(1.2,3.2)$ & $1.6(0.4,7.1)$ & $1.6(0.8,3.2)$ \\
\hline 11. Weekend drinking ${ }^{\#}$ & $\begin{array}{l}\text { More alcohol on } \\
\text { weekend }\end{array}$ & $1.1(0.9,1.4)$ & $1.1(0.9,1.4)$ & $1.4(1.0,2.0)$ & $1.4(1.0,1.8) * *$ \\
\hline
\end{tabular}


Note: CES-D-10: Center for Epidemiological Studies Short Form Depression Scale (10 items). OR: Odds ratio. CI: Confidence interval.

1- Age was not a significant factor. Variables $2-4$ are components of the base model when each of these variables is significant; variables 5-8 are inserted into the base model one at a time due to multicollinearity; variables $9-11$ are inserted one at a time into the base model plus race (variable 4). Reference group: (1) at home with family, friends or a spouse. (2) less than 12 years

formal education, (3) former or never, 4, and 5 White, (6) non-Latino, (7) English, (8) current, (9) 1-4 drinks, (10) no more alcohol on weekend. ${ }^{\#}$ non-drinkers have been excluded. *: significant at $\mathrm{p}<0.05, * *$ : significant at $\mathrm{p}<0.01$.

This article is protected by copyright. All rights reserved. 


\section{University Library}

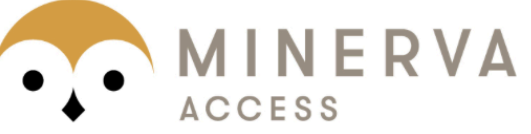

A gateway to Melbourne's research publications

Minerva Access is the Institutional Repository of The University of Melbourne

Author/s:

Mohebbi, M;Agustini, B;Woods, RL;McNeil, JJ;Nelson, MR;Shah, RC;Van, N;Storey,

E;Murray, AM;Reid, CM;Kirpach, B;Wolfe, R;Lockery, JE;Berk, M

Title:

Prevalence of depressive symptoms and its associated factors among healthy communitydwelling older adults living in Australia and the United States

Date:

2019-08-01

Citation:

Mohebbi, M., Agustini, B., Woods, R. L., McNeil, J. J., Nelson, M. R., Shah, R. C., Van, N., Storey, E., Murray, A. M., Reid, C. M., Kirpach, B., Wolfe, R., Lockery, J. E. \& Berk, M. (2019). Prevalence of depressive symptoms and its associated factors among healthy communitydwelling older adults living in Australia and the United States. INTERNATIONAL JOURNAL OF GERIATRIC PSYCHIATRY, 34 (8), pp.1208-1216. https://doi.org/10.1002/gps.5119.

Persistent Link:

http://hdl.handle.net/11343/285842 